\title{
Metal-Metal Multiple Bonds with "Half-Bond" Components in Paramagnetic Organometallics of f-Block Metals: Cyclopentadienyluranium Carbonyls as Molecular Relatives of Diuranium
}

\author{
Ciprian Coşar, ${ }^{1}$ Amr A. A. Attia, ${ }^{2,3}$ Alexandru Lupan, ${ }^{3}{ }^{3}$ and R. Bruce King $*^{4}$ \\ ${ }^{1}$ Department of Biomolecular Physics, Faculty of Physics, Babeş-Bolyai University, \\ Cluj-Napoca, Romania \\ ${ }^{2}$ National Institute for Research and Development of Isotopic and Molecular \\ Technologies, Cluj-Napoca, Romania \\ ${ }^{3}$ Department of Chemistry, Faculty of Chemistry and Chemical Engineering, Babeş- \\ Bolyai University, Cluj-Napoca, Romania \\ ${ }^{4}$ Department of Chemistry, University of Georgia, Athens, Georgia, 30602
}

\begin{abstract}
The experimentally observed reductive CO coupling in organouranium systems observed by Cloke and co-workers makes of interest the exploration of the structures and thermochemistry of simple $\mathrm{Cp}_{2} \mathrm{U}_{2}(\mathrm{CO})_{n}(n=5,4,3,2)$ derivatives. In this connection, the low-energy $\mathrm{Cp}_{2} \mathrm{U}_{2}(\mathrm{CO})_{n}(n=2,3,4)$ structures contain two to four bridging $\eta^{2}-\mu-\mathrm{CO}$ groups supplemented, in some cases, by one or two terminal $\mathrm{CO}$ groups. No examples of $\mathrm{CO}$ coupling to form $\mathrm{C}_{2} \mathrm{O}_{2}$ ligands are found in any of these $\mathrm{Cp}_{2} \mathrm{U}_{2}(\mathrm{CO})_{n}$ structures in contrast to the previously studied $\mathrm{Cp}_{2} \mathrm{Th}_{2}(\mathrm{CO})_{4}$ system in which $\mathrm{CO}$ coupling to form $\mathrm{C}_{2} \mathrm{O}_{2}$ ligands is observed. The retention of uranium valence electrons in low-energy $\mathrm{Cp}_{2} \mathrm{U}_{2}(\mathrm{CO})_{n}(n=3,4)$ structures, even after partial donation of uranium electrons to reduce $\mathrm{Cp}$ to $\mathrm{Cp}^{-}$and $\mathrm{CO}$ to $\mathrm{CO}^{2-}$, leads to a rich and complicated variety of $\mathrm{U}-\mathrm{U}$ bonding modes as well as spin states from singlet to quintet. Of particular interest are uranium-uranium multiple bonds containing multiple single electron half-bond components in triplet and quintet spin state $\mathrm{Cp}_{2} \mathrm{U}_{2}(\mathrm{CO})_{n}$ structures. The formal uraniumuranium multiple bonds in such $\mathrm{Cp}_{2} \mathrm{U}_{2}(\mathrm{CO})_{n}$ structures exhibit some of the features of the quintuple bond of diuranium, $\mathrm{U}_{2}$, in which a typical $\sigma+2 \pi$ triple bond similar to the $C \equiv C$ triple bond of acetylene is supplemented by no less than four separate one-electron halfbonds. Thus the $\mathrm{U} \equiv \mathrm{U}$ bonds in the lowest energy $\mathrm{Cp}_{2} \mathrm{U}_{2}(\mathrm{CO})_{n}(n=2,3)$ structures can be interpreted as formal triple bonds of various types with unusually short bond distances of $\sim 2.5 \AA$ and Wiberg bond indices of $\sim 3$.
\end{abstract}

* Corresponding authors e-mails: alupan@chem.ubbcluj.ro (A. Lupan) and rbking@chem.uga.edu (R. B. King). 


\section{Introduction}

The d-block transition metals are well-known to form an immense variety of stable metal carbonyl derivatives ${ }^{1}$ as exemplified by $\mathrm{Ni}(\mathrm{CO})_{4}, \mathrm{Fe}(\mathrm{CO})_{5}$, and $\mathrm{M}(\mathrm{CO})_{6}(\mathrm{M}$ =- Cr, Mo, W). The low formal oxidation states on the metal atoms in many such species are stabilized by $\mathrm{d} \pi \rightarrow \mathrm{p} \pi^{*}$ back-bonding from the central metal to $\mathrm{p} \pi^{*}$ antibonding orbitals of the CO ligands, thereby removing electron density from the metal atom. 2,3,4 This back-bonding is a consequence of the strong reducing properties of the low formal oxidation states of the metal atoms. The bonding of CO groups to d-block transition metals almost exclusively uses only the carbon atom. Thus examples of stable d-block transition metal carbonyls with one or more CO groups bonded to the metal through the oxygen atom as well as the carbon atom are very rare.

The f-block metals, including the lanthanides and actinides, are even stronger reducing agents than the d-block metals. This leads to very limited chemistry of stable carbonyl derivatives of the f-block metals. Instead the strong back-bonding of the strongly reducing f-block metals to $\mathrm{CO}$ groups transfers enough electron density to the oxygen atoms so that they become significantly basic. As a result CO groups in carbonyl groups of the f-block metals are likely to use their oxygen atoms as well as their carbon atoms for ligand-metal bonding. Stable binary carbonyls of the lanthanides and actinides remain unknown.

Most of the experimental carbonyl chemistry of the f-block metals is that of uranium. Stable uranium carbonyl derivatives are mainly of the type $C \mathrm{p}_{3} \mathrm{UCO}$ where $\mathrm{Cp}$ corresponds to a suitably substituted cyclopentadienyl group. ${ }^{5,6,7,8}$ Binary f-block metal carbonyls are not found under ambient conditions but only in the gas phase or lowtemperature matrices. The thorium carbonyls $\mathrm{Th}(\mathrm{CO})_{n}(n=1 \text { to } 6)^{9,10}$ and uranium carbonyls $\mathrm{U}(\mathrm{CO})_{n}(n=1,2,6)^{11}$ have been obtained by reactions of $\mathrm{CO}$ with laserablated metal atoms. However, they are stable only in low-temperature matrices.

An interesting, and currently unique, aspect of uranium carbonyl chemistry is the tendency of carbon monoxide to undergo reductive coupling in organouranium systems to give uranium complexes containing oxocarbon ligands ${ }^{12}$ such as ethynediolate $\left(\mathrm{C}_{2} \mathrm{O}_{2}{ }^{2-}\right),{ }^{13}$ deltate $\left(\right.$ cyclo- $\left.\mathrm{C}_{3} \mathrm{O}_{3}{ }^{2-}\right),{ }^{14}$ and squarate $\left(\right.$ cyclo- $\left.\mathrm{C}_{4} \mathrm{O}_{4}{ }^{2-}\right) .{ }^{15}$ The organouranium system studied most extensively is the mixed uranium(III) sandwich compound $\left(\eta^{5}-\mathrm{Me}_{5} \mathrm{C}_{5}\right) \mathrm{U}\left(\eta^{8}-\mathrm{C}_{8} \mathrm{H}_{6}\left\{\mathrm{SiR}_{3}\right\}_{2}\right)$ containing both cyclopentadienyl and cyclooctatetraene ligands. However, similar reductive dimerization of $\mathrm{CO}$ to coordinated ethynediolate has also been observed upon reaction with the uranium(III) tris(amide) complex $\left[\left(\mathrm{Me}_{3} \mathrm{Si}\right)_{2} \mathrm{~N}_{3} \mathrm{U}^{16}\right.$ Mechanistic studies on the mixed sandwich system suggest that the 
reductive coupling process involves a binuclear uranium intermediate with a bridging ethynediolate group. ${ }^{17}$

Theoretical studies on organouranium carbonyl systems of the types $\mathrm{Cp}_{2} \mathrm{U}_{2}(\mathrm{CO})_{n}$ $\left(\mathrm{Cp}=\eta^{5}-\mathrm{C}_{5} \mathrm{H}_{5}\right), \quad\left(\eta^{8}-\mathrm{C}_{8} \mathrm{H}_{8}\right)_{2} \mathrm{U}_{2}(\mathrm{CO})_{n}$, and $\mathrm{Cp}\left(\eta^{8}-\mathrm{C}_{8} \mathrm{H}_{8}\right) \mathrm{U}_{2}(\mathrm{CO})_{n}$ are of interest for understanding the interactions of carbon monoxide with organouranium systems. However, these studies are complicated by the multiplicity of viable uranium oxidation states, namely $+3,+4,+5$, and +6 . This leads to a variety of possible spin states since all but $\mathrm{U}(\mathrm{VI})$ normally appear to be high-spin species. Thus $\mathrm{U}(\mathrm{III}), \mathrm{U}(\mathrm{IV})$, and $\mathrm{U}(\mathrm{V})$ are $\mathrm{f}^{3}$, $\mathrm{f}^{2}$, and $\mathrm{f}^{1}$ systems having 3,2 , and 1 unpaired electrons, respectively. This can lead to singlet, triplet, quintet, and septet spin states for binuclear organouranium carbonyls. Furthermore, in binuclear derivatives the possibility of uranium-uranium bonding needs to be considered.

The complexity of uranium-uranium bonding is illustrated by the unusual bonding in the bare uranium dimer $U_{2}$. Thus, the formal quintuple bond in $U_{2}$ consists of a normal $\sigma+2 \pi$ triple bond similar to the $\mathrm{C} \equiv \mathrm{C}$ triple bond in acetylene, supplemented by four single-electron "half bonds" ${ }^{18,19}$ This, coupled with two unpaired non-bonding electrons leads to a septet ground state for $\mathrm{U}_{2}$.

A very recent computational study investigated the permethylated dimetallocenes $\left(\mathrm{Cp}^{*}{ }_{2} \mathrm{M}_{2}\left(\mathrm{M}=\mathrm{Th}, \mathrm{Pa}, \mathrm{U}, \mathrm{Np}, \mathrm{Pu}\right.\right.$; $\left.\mathrm{Cp} *=-\eta^{5}-\mathrm{Me}_{5} \mathrm{C}_{5}\right) \cdot{ }^{20} \mathrm{~A}$ nonet spin state with a $\sigma+{ }^{2} / 2 \pi$ $+2 / 2 \delta$ triple $U \equiv U$ bond was found for the ground state for $\mathrm{Cp}^{*}{ }_{2} \mathrm{U}_{2}$. This formal triple bond, containing four one-electron "half bonds", leaves four of the original eight unpaired electrons from the nonet spin state to be divided between the two uranium atoms. This corresponds to the formal $f^{2} \mathrm{U}(\mathrm{IV})$ oxidation state.

In order to avoid these complexities of uranium chemistry in our initial studies, we first chose to investigate the corresponding thorium derivatives. ${ }^{21,22}$ Unlike uranium chemistry, thorium chemistry consists almost entirely of the diamagnetic $f^{0}$ Th(IV) oxidation state. Thus the chemistry of binuclear organothorium carbonyls is likely to consist of mainly singlet spin state structures with an occasional triplet spin state structure. For the $\mathrm{Cp}_{2} \mathrm{Th}_{2}(\mathrm{CO})_{3}$ system the favored +4 thorium oxidation state and the anionic nature of the $\mathrm{Cp}^{-}$ligand with six $\pi$ electrons leads to a -6 charge on the central bridging $(\mathrm{CO})_{3}$ unit. This -6 charge can be distributed equally between the three bridging CO ligands in the tricarbonyl $\mathrm{Cp}_{2} \mathrm{Th}_{2}(\mathrm{CO})_{3}$ leading to dianionic $\mathrm{CO}^{2-}$ ligands, derived, in principle, from the double deprotonation of hydroxymethylene, $\mathrm{HC}(\mathrm{OH})$ or its tautomer formaldehyde $\mathrm{HC}(\mathrm{O}) \mathrm{H}$. Such bridging $\mathrm{CO}^{2-}$ ligands are $\eta^{2}-\mu-\mathrm{CO}$ ligands, bonded to one thorium through the carbon atoms and to the other thorium through both the carbon and oxygen atoms. The predicted 3.7 to $3.9 \AA \mathrm{Th}{ }^{\cdots}{ }^{\cdots} \mathrm{Th}$ distances in these $\mathrm{Cp}_{2} \mathrm{Th}_{2}(\mathrm{CO})_{3}$ 
structures are long enough to imply the absence of a formal Th-Th bond. For the dicarbonyl $\mathrm{Cp}_{2} \mathrm{Th}_{2}(\mathrm{CO})_{2}$, the similar consideration of the two bridging $\eta^{2}-\mu$-CO ligands as dianions leads to a formal Th(III) oxidation state of +3 . The single $f$ electrons in each Th(III) unit can then couple to give a formal Th-Th single bond, consistent with shortening the Th-Th distance to 3.3 to $3.4 \AA$.

The two extra valence electrons on uranium relative to thorium create considerable additional complications for the metal-metal bonding in binuclear $\mathrm{Cp}_{2} \mathrm{U}_{2}(\mathrm{CO})_{n}$ derivatives. Consider, for example, $\mathrm{Cp}_{2} \mathrm{U}_{2}\left(\eta^{2}-\mu-\mathrm{CO}\right)_{3}$ analogous to the previously studied ${ }^{21} \mathrm{Cp}_{2} \mathrm{Th}_{2}\left(\eta^{2}-\mu-\mathrm{CO}\right)_{3}$. Assuming $\mathrm{CO}^{2-}$ ligands in $\mathrm{Cp}_{2} \mathrm{U}_{2}\left(\eta^{2}-\mu-\mathrm{CO}\right)_{3}$ leads to an $\mathrm{f}^{2}$ formal +4 oxidation state for the uranium atoms. The four electrons from the two $\mathrm{f}^{2} \mathrm{U}(\mathrm{IV})$ atoms in such a binuclear $\mathrm{Cp}_{2} \mathrm{U}_{2}\left(\eta^{2}-\mu-\mathrm{CO}\right)_{3}$ derivative can be used to form uranium-uranium bonds of various types. Using all four of these electrons for uranium-uranium bonding leads to a formal $\mathrm{U}=\mathrm{U}$ double bond. Such a $\mathrm{U}=\mathrm{U}$ double bond in a singlet $\mathrm{Cp}_{2} \mathrm{U}_{2}\left(\eta^{2}-\mu-\mathrm{CO}\right)_{3}$ structure can be a $\sigma+\pi$ bond similar to the $\mathrm{C}=\mathrm{C}$ double bond in ethylene. In a triplet $\mathrm{Cp}_{2} \mathrm{U}_{2}\left(\eta^{2}-\mu-\mathrm{CO}\right)_{3}$ structure the formal $\mathrm{U}=\mathrm{U}$ double bond can be a $\sigma+2 / 2 \pi$ bond analogous to the $\mathrm{O}=\mathrm{O}$ double bond in triplet dioxygen or the $\mathrm{Fe}=\mathrm{Fe}$ double bond in the experimentally known stable organometallics $\left(\eta^{5}-\mathrm{R}_{5} \mathrm{C}_{5}\right)_{2} \mathrm{Fe}_{2}(\mu-\mathrm{CO})_{3}$ $\left(\mathrm{R}=\mathrm{H}, \mathrm{CH}_{3}\right){ }^{23,24,25}$ The availability of both $\mathrm{d}$ and $\mathrm{f}$ orbitals as uranium valence orbitals even makes feasible a quintet $\mathrm{Cp}_{2} \mathrm{U}_{2}\left(\eta^{2}-\mu-\mathrm{CO}\right)_{3}$ structure in which the formal $\mathrm{U}=\mathrm{U}$ double bond is composed of four orthogonal single-electron "half bonds" related to the four single-electron "half-bond" components of the formal U-U quintuple bond in bare diuranium, $\mathrm{U}_{2}{ }^{18,19}$ Binuclear organouranium compounds can thus provide examples of paramagnetic organometallic molecules in which metal-metal multiple bonds contain some or all of the unpaired electrons. Such metal-metal multiple bonds can include multiple single-electron half-bond components containing some of the unpaired electrons of the paramagnetic structure.

Another important difference between uranium and thorium chemistry is the availability of the +5 and +6 oxidation states for uranium but not for thorium. However, these higher formal oxidation states do not appear to be accessible in $\mathrm{Cp}_{2} \mathrm{U}_{2}(\mathrm{CO})_{n}(n=2$, $3,4,5)$ derivatives. In other words, uranium(IV) is not a strong enough reducing agent to reduce neutral $\mathrm{CO}$ groups to anions with concurrent oxidation to uranium(V) or uranium(VI). Thus the chemistry of the $\mathrm{Cp}_{2} \mathrm{U}_{2}(\mathrm{CO})_{n}$ derivatives, particularly the uranium-uranium interactions and preferred spin states, can be interpreted with both uranium atoms limited to the formal +3 or +4 oxidation states rather than the higher +5 or +6 oxidation states. 
This paper reports a comprehensive density functional theory study of $\mathrm{Cp}_{2} \mathrm{U}_{2}(\mathrm{CO})_{n}(n=2,3,4,5)$ systems. This study has uncovered a variety of novel paramagnetic structures containing formal uranium-uranium multiple bonds including up to four single-electron half-bond components.

\section{Theoretical Methods}

The initial $\mathrm{Cp}_{2} \mathrm{U}_{2}(\mathrm{CO})_{n}(n=2,3)$ structures were constructed by systematic placement of $\mathrm{CO}$ ligands as terminal $\mathrm{CO}$ and bridging $\mathrm{CO}$ ligands coordinating through only the carbon atom or through both the carbon and oxygen atoms (see the Supporting Information). This led to 16 different starting structures for $\mathrm{Cp}_{2} \mathrm{U}_{2}(\mathrm{CO})_{2}$ and 57 starting structures for $\mathrm{Cp}_{2} \mathrm{U}_{2}(\mathrm{CO})_{3}$, all computed as singlets, triplets, quintets, and septets. For the more complicated $\mathrm{Cp}_{2} \mathrm{U}_{2}(\mathrm{CO})_{4}$ and $\mathrm{Cp}_{2} \mathrm{U}_{2}(\mathrm{CO})_{5}$ systems the corresponding $\mathrm{Cp}_{2} \mathrm{Th}_{2}(\mathrm{CO})_{n}$ $(n=4,5)$ structures ${ }^{17}$ were reoptimized substituting uranium for thorium.

Full geometry optimizations were carried out on the $\mathrm{Cp}_{2} \mathrm{U}_{2}(\mathrm{CO})_{n}$ systems by using the BP86 DFT functional coupled with the TZVP basis set for all atoms except uranium for which the ECP60MWB basis set including pseudopotentials was used. $^{26,27,28,29,30,31,32}$ In addition, geometry optimizations were also carried out using the M06-L and the PBE0 DFT functionals providing qualitatively very similar results. The M06-L and the PBE0 optimized structures can be found as concatenated xyz coordinates in the Supporting Information, whereas the BP86 data are reported in the Tables. The nature of the stationary points after optimization was checked by calculations of the harmonic vibrational frequencies. If significant imaginary frequencies were found, the optimization was continued by following the corresponding normal modes to insure that genuine minima were obtained. In addition, single point energy calculations were performed on all optimized structures by utilizing the BP86 DFT functional and the def2-TZVP basis set coupled with the zero-order regular approximation (ZORA) ${ }^{33,34}$ as implemented in the ORCA 3.0.3 software package ${ }^{35}$. These calculations were performed using very tight convergence criteria; the resulting energetics are discussed in the text.

All geometry optimizations were performed using the Gaussian 09 package ${ }^{36}$ with the default settings for the SCF cycles and geometry optimization, and a very fine $(120,974)$ grid for numerically evaluating the integrals, $10^{-8}$ hartree for the self-consistent field convergence, maximum force of 0.000450 hartree/bohr, RMS force of 0.000300 hartree/bohr, maximum displacement of 0.001800 bohr, and RMS displacement of 0.001200 bohr. Wiberg bond indices (WBIs) for the U-U interactions in the optimized $\mathrm{Cp}_{2} \mathrm{U}_{2}(\mathrm{CO})_{n}$ structures determined using $\mathrm{NBO}$ analysis ${ }^{37}$ were used since they are well- 
established as means for evaluating M-M interactions. In addition U-U Mayer bond order values (MBOs) ${ }^{38}$ were determined.

The structures, total and relative energies, and relevant interatomic distances for all of the optimized structures are given in the Supporting Information. Structures are numbered as $\mathbf{n A - x}$ where $\mathbf{n}$ refers to the number of CO groups, $\mathbf{A}$ refers to the spin state with $\mathbf{S}, \mathbf{T}$, and $\mathbf{Q}$ corresponding to singlet, triplet, and quintet spin states, respectively, and $\mathbf{x}$ orders the structures according to their relative energies. Isomeric structures that are similar relative to spin state and approximate $U-U$ distances are differentiated by their Cp-U-U-Cp dihedral angles where Cp refers to the centroid of a cyclopentadienyl ring. Only the lowest energy and thus potentially chemically significant structures (Figures 1, 3, 4, 5 and Tables 1 to 4) are considered in detail in this paper. However, more comprehensive lists of structures, including higher energy structures, are given in the Supporting Information.

\section{Results and Discussion}

\subsection{General Comments}

The formal U-U bond orders in the $\mathrm{Cp}_{2} \mathrm{U}_{2}(\mathrm{CO})_{n}$ structures can be inferred based on the U-U distances, Wiberg bond indices (WBIs) as determined by NBO analyses, ${ }^{37}$ and Mayer bond orders (MBOs). ${ }^{38}$ Analysis of the frontier molecular orbitals is not useful for confirming the formal bond orders suggested by these methods because of interaction of the uranium-uranium bond with the bridging carbonyl groups in all of the $\mathrm{Cp}_{2} \mathrm{U}_{2}(\mathrm{CO})_{n}$ structures. However, the frontier molecular orbitals for all of the optimized structures are given in the Supporting Information.

In the $\mathrm{Cp}_{2} \mathrm{U}_{2}(\mathrm{CO})_{n}$ systems, as in the related $\mathrm{Cp}_{2} \mathrm{Th}_{2}(\mathrm{CO})_{n}$ systems, ${ }^{21}$ the $\mathrm{WBI}$ values are close to the actual formal $U-U$ bond order. However, for singlet structures the WBI values slightly underestimate the formal bond orders whereas for triplet and most quintet structures the WBI values slightly overestimate the formal bond orders. The relationship of the WBIs of metal-metal bonds to formal bond orders between f-block metals are completely different than the WBIs of metal-metal bonds between d-block transition metals, which are typically 20 to 30\% of the formal bond orders. ${ }^{39}$

Formal U-U single bonds can consist of either two paired electrons in a single molecular orbital or two single-electron "half bonds" with the electrons remaining unpaired in two different molecular orbitals. Similarly, formal $\mathrm{U}=\mathrm{U}$ double bonds can have two two-electron single bond components like the $\mathrm{C}=\mathrm{C}$ double bond in ethylene or one two-electron single bond and two one-electron half bonds such as in triplet dioxygen or the organometallic $\mathrm{Cp}_{2} \mathrm{Fe}_{2}(\mu-\mathrm{CO})_{3} \cdot{ }^{23,24,25}$ The $\mathrm{U}-\mathrm{U}$ formal single bonds in low-energy 
$\mathrm{Cp}_{2} \mathrm{U}_{2}(\mathrm{CO})_{n}$ structures have lengths ranging from $\sim 3.3$ to $\sim 3.5 \AA$ with WBIs ranging from $\sim 1.0$ to $\sim 1.2$. Formal $\mathrm{U}=\mathrm{U}$ double bonds are not found in the lowest energy $\mathrm{Cp}_{2} \mathrm{U}_{2}(\mathrm{CO})_{n}$ structures. When they occur, they are found to have WBIs of $\sim 1.8$ and lengths comparable to $\mathrm{U}-\mathrm{U}$ single bonds. Formal $\mathrm{U} \equiv \mathrm{U}$ triple bonds are much shorter than $\mathrm{U}-\mathrm{U}$ single or $\mathrm{U}=\mathrm{U}$ double bonds with lengths ranging from 2.36 to $2.50 \AA$ corresponding to WBIs from 2.8 to $~ 3.4$.

After inferring formal U-U bond orders based on U-U distances, WBIs, and MBOs, the compositions of the U-U bonds, including multiple bonds, can be related to the molecular spin state. Using this approach, the U-U bonds in $\mathrm{Cp}_{2} \mathrm{U}_{2}(\mathrm{CO})_{n}$ derivatives can be dissected into a combination of normal two-electron bonds and single-electron "half-bonds." This is analogous to the reported dissection of the U-U bonding in the bare uranium dimer, $\mathrm{U}_{2}$, into three two-electron bonds corresponding to a normal $\sigma+2 \pi$ triple bond similar to acetylene supplemented by four single-electron half-bonds. However, complications originating from the set of bridging $\eta^{2}-\mu-\mathrm{CO}$ groups in the $\mathrm{Cp}_{2} \mathrm{U}_{2}(\mathrm{CO})_{n}$ structures make the formal metal-metal bond orders rarely apparent from the frontier molecular orbitals.

The $\mathrm{MBOs}^{38}$ are useful for distinguishing different types of $\mathrm{U} \equiv \mathrm{U}$ triple bonds relating to the spin states. Thus the $\mathrm{U} \equiv \mathrm{U}$ triple bond in the singlet $\mathrm{Cp}_{2} \mathrm{U}_{2}(\mathrm{CO})_{2}$ structure 2S-1 has an MBO of 3.02 essentially identical with the formal bond order. However, the $2+2 / 2$ type $\mathrm{U} \equiv \mathrm{U}$ triple bonds in the triplet $\mathrm{Cp}_{2} \mathrm{U}_{2}(\mathrm{CO})_{n}(n=3,2)$ structures $\mathbf{3 T}-\mathbf{1}$ and 2T-2 have MBOs of $\sim 2.3$ whereas the $1+4 / 2 \mathrm{U} \equiv \mathrm{U}$ triple bond in the $\mathrm{Cp}_{2} \mathrm{U}_{2}(\mathrm{CO})_{3}$ structure 3Q-2 has an even lower MBO value of 1.91. In general, MBO values for formal $\mathrm{U}=\mathrm{U}$ double bonds range from 1.2 to 1.3 and those for formal $\mathrm{U}-\mathrm{U}$ single bonds from 0.8 to 1.2 .

The Mulliken spin densities are higher for the uranium atoms bonded to the oxygen atoms of the $\mathrm{CO}$ groups than for the uranium atoms bonded exclusively to carbon atoms of $\mathrm{CO}$ groups. This can be related to the higher electronegativity of oxygen relative to carbon.

\subsection{The $\mathrm{Cp}_{2} \mathrm{U}_{2}(\mathrm{CO})_{4}$ structures.}

The two lowest energy $\mathrm{Cp}_{2} \mathrm{U}_{2}(\mathrm{CO})_{4}$ structures have four separate bridging $\eta^{2}$ - $\mu$-CO groups oriented in the same direction across the uranium-uranium bond. Considering the uranium atoms in these structures to be in the $f^{2} \mathrm{U}(\mathrm{IV})$ oxidation state leaves two electrons on each uranium atom to participate in the uranium-uranium bonding (Figure 1 and Table 1). The lowest energy $\mathrm{Cp}_{2} \mathrm{U}_{2}(\mathrm{CO})_{4}$ structure 4T-1 with all CO groups has a $\mathrm{U}-\mathrm{U}$ distance of $3.419 \AA$, a WBI of 1.24 , and an MBO of 0.88 
suggesting a formal single bond pairing two of the four uranium electrons. This leaves one unpaired electron on each uranium atom to account for the triplet spin state.

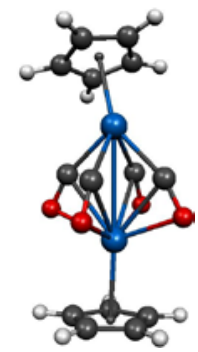

4T-1

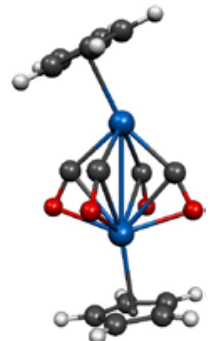

4S-2

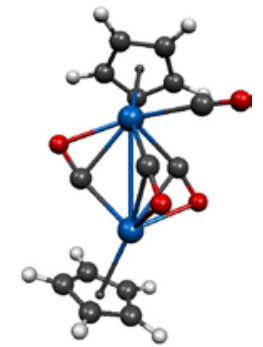

4T-3

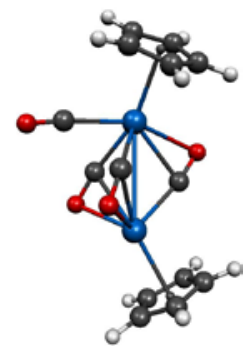

4Q-4

\section{$0.0 \mathrm{kcal} / \mathrm{mol} \quad 11.1 \mathrm{kcal} / \mathrm{mol} \quad 12.2 \mathrm{kcal} / \mathrm{mol} \quad 14.8 \mathrm{kcal} / \mathrm{mol}$}

Figure 1. The three optimized $\mathrm{Cp}_{2} \mathrm{U}_{2}(\mathrm{CO})_{4}$ structures within $17 \mathrm{kcal} / \mathrm{mol}$ of the global minimum.

The uneven distribution of the Mulliken spin densities in 4T-1 between the two uranium atoms is supported by analysis of the frontier molecular orbitals. Thus single electron in the highest energy half-filled molecular orbital (SOMO in Figure 2) is distributed over both uranium atoms whereas the single electron in the other half-filled molecular orbital (SOMO-1 in Figure 2) is localized on the uranium atom on the oxygen side of the $\left(\eta^{2}-\mu-C O\right)_{4}$ bridging unit (bottom uranium atom in Figure 2). This is consistent with the bottom uranium atom having a Mulliken spin density of 1.64 and the top uranium atom having a Mulliken spin density of only 0.55 and relates to the higher electronegativity of oxygen relative to carbon in the bridging $\mathrm{CO}$ groups.

Table 1. The four $\mathrm{Cp}_{2} \mathrm{U}_{2}(\mathrm{CO})_{4}$ structures up to $17 \mathrm{kcal} / \mathrm{mol}$ in energy.

\begin{tabular}{cccccccc}
\hline Structure & $\begin{array}{c}\Delta \mathrm{E} \\
(\mathrm{kcal} / \mathrm{mol})\end{array}$ & $\begin{array}{c}\mathrm{U}-\mathrm{U} \text { distance } \\
(\AA)\end{array}$ & $\begin{array}{c}\text { Wiberg bond } \\
\text { index }(\mathrm{WBI})\end{array}$ & $\begin{array}{c}\text { Mayer bond } \\
\text { Order (MBO) }\end{array}$ & $\begin{array}{c}\text { U-U bond } \\
\text { order }\end{array}$ & $\begin{array}{c}\text { Mulliken } \\
\text { spin density }^{\mathrm{a}}\end{array}$ & $\begin{array}{c}\text { Cp-U-U-Cp } \\
\text { Dihedral, }^{\circ}\end{array}$ \\
\hline $\mathbf{4 T - 1}\left(C_{4 v}\right)$ & 0.0 & 3.419 & 1.24 & 0.88 & 1 & $0.55 / 1.64$ & 77.7 \\
$\mathbf{4 S - 2}\left(C_{4 v}\right)$ & 11.1 & 3.367 & 1.87 & 1.32 & 2 & - & 180.0 \\
$\mathbf{4 T - 3}\left(C_{1}\right)$ & 12.2 & 3.403 & 1.14 & 0.87 & 1 & $2.32 /-0.53$ & 56.3 \\
$\mathbf{4 Q - 4}\left(C_{s}\right)$ & 14.8 & 3.449 & 1.00 & 0.82 & $2 / 2$ & $2.51 / 1.54$ & 71.4 \\
\hline
\end{tabular}

${ }^{\mathrm{a}}$ The spin density of the uranium atom bonded to the carbon side of the bridging $\left(\eta^{2}-\mu-\mathrm{CO}\right)_{4}$ unit is listed first.

The triplet $\mathrm{Cp}_{2} \mathrm{U}_{2}\left(\eta^{2}-\mu-\mathrm{CO}\right)_{4}$ structure $\mathbf{4 T - 1}$ is obviously a very favorable structure since it lies $\sim 11 \mathrm{kcal} / \mathrm{mol}$ in energy below the next lowest energy $\mathrm{Cp}_{2} \mathrm{U}_{2}(\mathrm{CO})_{4}$ structure, namely the singlet structure $4 \mathrm{~S}-2$. The high WBI of 1.87 in $\mathbf{4 S - 2}$ suggests that 
all four electrons in the two U(IV) atoms in $\mathbf{4 S - 2}$ are fully paired to form a $\mathrm{U}=\mathrm{U}$ double bond consistent with the singlet spin state (Figure 1 and Table 1).

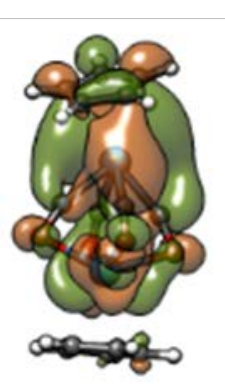

LUMO+1

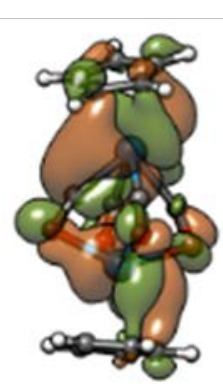

LUMO

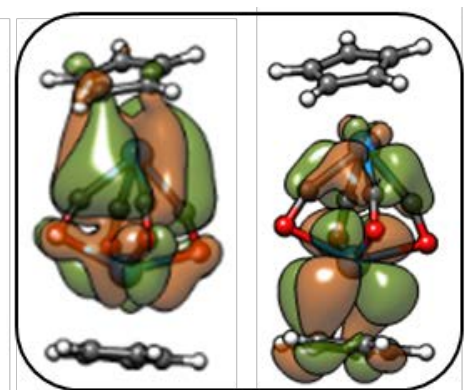

SOMO SOMO-1

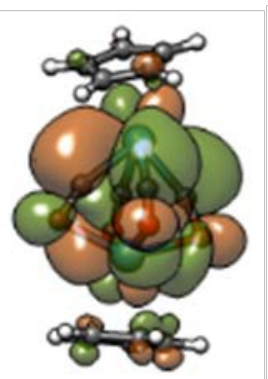

HOMO-2

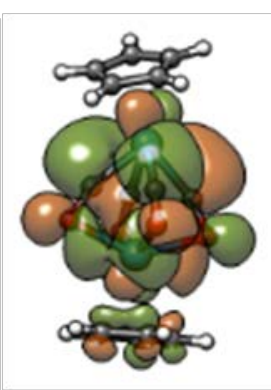

HOMO-3

Figure 2. The frontier molecular orbitals of the triplet $\mathrm{Cp}_{2} \mathrm{U}_{2}(\mathrm{CO})_{4}$ structure 4T-1. The two half-occupied molecular orbitals (SOMO and SOMO-1) are enclosed in a rectangle.

The third $\mathrm{Cp}_{2} \mathrm{U}_{2}(\mathrm{CO})_{4}$ structure 4T-3, lying $12.2 \mathrm{kcal} / \mathrm{mol}$ in energy above $\mathbf{4 T - 1}$, has only three bridging $\eta^{2}-\mu$-CO groups and one terminal CO group (Figure 1 and Table 1). The U-U distance of $\sim 3.40 \AA$ with a corresponding WBI of 1.14 and $\mathrm{MBO}$ of 0.87 in 4T-3 corresponds to a formal single bond thereby pairing two of the uranium $f$ electrons. The remaining two f electrons remain as unpaired electrons accounting for the triplet spin state. The fourth $\mathrm{Cp}_{2} \mathrm{U}_{2}(\mathrm{CO})_{4}$ structure 4Q-4, lying $14.8 \mathrm{kcal} / \mathrm{mol}$ in energy above 4T-1, has a similar arrangement of CO groups as 4T-3 but with a quintet spin state. The U-U distance of $\sim 3.45 \AA$ with a corresponding WBI of 1.00 and $\mathrm{MBO}$ of 0.82 suggests a formal single bond. However, the $\mathrm{U}-\mathrm{U}$ single bond in 4Q-4 must consist of two orthogonal "half-bond" one-electron components to preserve the overall quintet spin state.

\subsection{The $\mathrm{Cp}_{2} \mathrm{U}_{2}(\mathrm{CO})_{3}$ structures.}

The two lowest energy $\mathrm{Cp}_{2} \mathrm{U}_{2}(\mathrm{CO})_{3}$ structures have three bridging $\eta^{2}-\mu-\mathrm{CO}$ groups with two oriented in one direction and the third oriented in the other direction (Figure 3 and Table 2). Both structures have very short $U \equiv U$ distances of $\sim 2.5 \AA$ and high WBIs of $\sim 3$ suggesting formal metal-metal triple bonds. Since six uranium electrons are required to form a $\mathrm{U} \equiv \mathrm{U}$ triple bond this implies a formal oxidation state of each uranium atom no higher than the $\mathrm{f}^{3} \mathrm{U}(\mathrm{III})$ in order to have enough electrons for the triple bond. The lowest energy $\mathrm{Cp}_{2} \mathrm{U}_{2}(\mathrm{CO})_{3}$ structure $\mathbf{3 T - 1}$ is a triplet structure. In order to preserve the triplet spin state the $\mathrm{U} \equiv \mathrm{U}$ triple bond is a $2+\frac{2}{2}$ bond with two two-electron bond components and two one-electron "half-bond" components. The next higher energy $\mathrm{Cp}_{2} \mathrm{U}_{2}(\mathrm{CO})_{3}$ structure $\mathbf{3 Q}$-2, lying $8.3 \mathrm{kcal} / \mathrm{mol}$ in energy above $\mathbf{3 T - 1}$, is a quintet 
structure. In order to preserve the quintet spin state the $\mathrm{U} \equiv \mathrm{U}$ triple bond becomes a $1+4 / 2$ bond with only one two-electron bond component and four one-electron "halfbond" components. The four half-bond components in 3Q-2 can be similar to those found in diuranium. ${ }^{18,19}$ The MBO values for the $\mathrm{U} \equiv \mathrm{U}$ interactions in 3T-1 and 3Q-2 of 2.33 and 1.91, respectively, are increasingly below the formal bond order of 3 as the number of one-electron "half-bond" components is increased. This suggests that the halfbond components of the $2+2 / 2$ and $1+4 / 2$ formal $U \equiv U$ triple bonds represent individual interactions that are significantly weaker than half of the full two-electron U-U bond components.

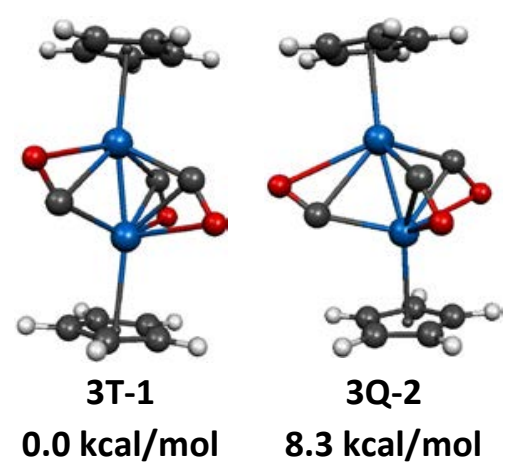

Figure 3. The two lowest energy $\mathrm{Cp}_{2} \mathrm{U}_{2}(\mathrm{CO})_{3}$ structures.

Table 2. The two $\mathrm{Cp}_{2} \mathrm{U}_{2}(\mathrm{CO})_{3}$ structures up to $17 \mathrm{kcal} / \mathrm{mol}$ in energy

\begin{tabular}{cccccccc}
\hline Structure & $\begin{array}{c}\Delta \mathrm{E} \\
(\mathrm{kcal} / \mathrm{mol})\end{array}$ & $\begin{array}{c}\mathrm{U}-\mathrm{U} \\
\text { distance }(\AA)\end{array}$ & $\begin{array}{c}\text { Wiberg bond } \\
\text { index (WBI) }\end{array}$ & $\begin{array}{c}\text { Mayer bond } \\
\text { order }(\mathrm{MBO})\end{array}$ & $\begin{array}{c}\text { U-U bond } \\
\text { order }\end{array}$ & $\begin{array}{c}\text { Mulliken } \\
\text { spin density }^{\mathrm{a}}\end{array}$ & $\begin{array}{c}\text { Cp-U-U-Cp } \\
\text { Dihedral, }^{\circ}\end{array}$ \\
\hline $\mathbf{3 T - 1}$ & 0.0 & 2.441 & 3.41 & 2.33 & $2+2 / 2$ & $1.15 / 0.72$ & 172.4 \\
$\mathbf{3 Q - 2}$ & 8.3 & 2.497 & 2.89 & 1.91 & $1+4 / 2$ & $1.72 / 1.76$ & 134.2 \\
\hline
\end{tabular}

${ }^{a}$ The spin density of the uranium atom directly bonded to the most oxygen atoms is listed first.

\subsection{The $\mathrm{Cp}_{2} \mathrm{U}_{2}(\mathrm{CO})_{2}$ structures.}

The two lowest-energy $\mathrm{Cp}_{2} \mathrm{U}_{2}(\mathrm{CO})_{2}$ structures each have two bridging $\eta^{2}-\mu-\mathrm{CO}$ groups oriented in the same direction (Figure 4 and Table 3). Similar to $\mathrm{Cp}_{2} \mathrm{U}_{2}(\mathrm{CO})_{3}$, both $\mathrm{Cp}_{2} \mathrm{U}_{2}(\mathrm{CO})_{2}$ structures have short $\sim 2.4 \AA \mathrm{U} \equiv \mathrm{U}$ distances corresponding to WBIs of $\sim 3$. This suggests formal triple bonds implying a formal uranium oxidation state no higher than the $\mathrm{f}^{3} \mathrm{U}(\mathrm{III})$. The lowest energy $\mathrm{Cp}_{2} \mathrm{U}_{2}(\mathrm{CO})_{2}$ structure is the singlet 2S-1 in which the $\mathrm{U} \equiv \mathrm{U}$ triple bond has three two-electron bond components and an $\mathrm{MBO}$ of 3.02 equal to the formal bond order. The next $\mathrm{Cp}_{2} \mathrm{U}_{2}(\mathrm{CO})_{3}$ structure is the triplet 2T-2, lying $5.6 \mathrm{kcal} / \mathrm{mol}$ in energy above $\mathbf{2 S}-\mathbf{1}$. In $\mathbf{2} \mathbf{T}-\mathbf{2}$ the $\mathrm{U} \equiv \mathrm{U}$ triple bond must necessarily consist of only two two-electron bond components as well as two one-electron "half-bonds" in 
order to preserve the triplet spin state. The $\mathrm{MBO}$ of 2.39 for the $\mathrm{U} \equiv \mathrm{U}$ in $2 \mathrm{~T}-2$ relative to the corresponding $\mathrm{MBO}$ of 3.02 in 2S-1 reflects the weakness of the two half-bond single-electron interactions in $\mathbf{2 T - 2}$ relative to the third two-electron $\mathrm{U}-\mathrm{U}$ component in the formal $\mathrm{U} \equiv \mathrm{U}$ triple bond of $\mathbf{2 S} \mathbf{- 1}$.

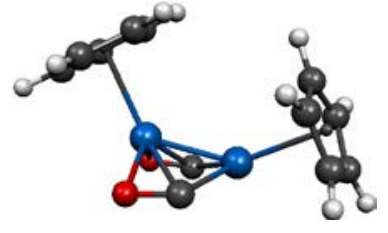

2S-1

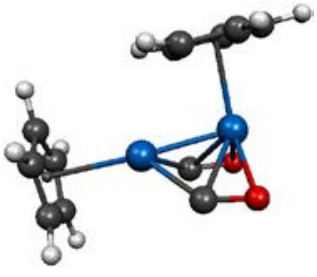

2T-2

\section{$0.0 \mathrm{kcal} / \mathrm{mol} \quad 5.6 \mathrm{kcal} / \mathrm{mol}$}

Figure 4. The two lowest energy $\mathrm{Cp}_{2} \mathrm{U}_{2}(\mathrm{CO})_{2}$ structures.

Table 3. The $\mathrm{Cp}_{2} \mathrm{U}_{2}(\mathrm{CO})_{2}$ structures up to $17 \mathrm{kcal} / \mathrm{mol}$ in energy.

\begin{tabular}{cccccccc}
\hline Structure & $\begin{array}{c}\Delta \mathrm{E} \\
(\mathrm{kcal} / \mathrm{mol})\end{array}$ & $\begin{array}{c}\mathrm{U}-\mathrm{U} \\
\text { distance }(\AA)\end{array}$ & $\begin{array}{c}\text { Wiberg bond } \\
\text { index }(\mathrm{WBI})\end{array}$ & $\begin{array}{c}\text { Mayer bond } \\
\text { order }(\mathrm{MBO})\end{array}$ & $\begin{array}{c}\text { U-U bond } \\
\text { order }\end{array}$ & $\begin{array}{c}\text { Mulliken } \\
\text { spin density }^{\mathrm{a}}\end{array}$ & $\begin{array}{c}\text { Cp-U-U-Cp } \\
\text { Dihedral, }^{\circ}\end{array}$ \\
\hline $\mathbf{2 S - 1}$ & 0.0 & 2.363 & 2.83 & 3.02 & 3 & - & 29.2 \\
$\mathbf{2 T - 2}$ & 5.6 & 2.387 & 3.25 & 2.39 & $2+2 / 2$ & $0.45 / 1.49$ & 72.1 \\
\hline
\end{tabular}

${ }^{\mathrm{a}}$ The spin density of the uranium atom directly bonded to the most carbon atoms is listed first.

\subsection{The $\mathrm{Cp}_{2} \mathrm{U}_{2}(\mathrm{CO})_{5}$ structures.}

Three low-energy $\mathrm{Cp}_{2} \mathrm{U}_{2}(\mathrm{CO})_{5}$ structures were found within $11 \mathrm{kcal} / \mathrm{mol}$ of the lowest energy structure (Figure 5 and Table 4). The two lowest-energy $\mathrm{Cp}_{2} \mathrm{U}_{2}(\mathrm{CO})_{5}$ structures have four separate bridging $\eta^{2}-\mu-\mathrm{CO}$ groups oriented in the same direction similar to the corresponding $\mathrm{Cp}_{2} \mathrm{U}_{2}\left(\eta^{2}-\mu-\mathrm{CO}\right)_{4}$ structures (Figure 1). The fifth CO group is bonded as a terminal ligand to the uranium atom on the carbon side of the four bridging $\eta^{2}$ - $\mu$-CO groups. Both of these $\mathrm{Cp}_{2} \mathrm{U}_{2}(\mathrm{CO})_{5}$ structures have U-U distances of $\sim 3.4 \AA$ corresponding to WBIs of $\sim 1$ thereby suggesting formal single bonds. In the lowest energy $\mathrm{Cp}_{2} \mathrm{U}_{2}(\mathrm{CO})_{5}$ structure $\mathbf{5 T - 1}$ formation of a $\mathrm{U}-\mathrm{U}$ single bond using with the uranium in the $\mathrm{f}^{2} \mathrm{U}(\mathrm{IV})$ oxidation state leaves one unpaired electron on each uranium atom corresponding to the triplet spin state. The high $\mathrm{MBO}$ of 1.77 for the $\mathrm{U}-\mathrm{U}$ interaction in 5T-1 relative to the WBI of 1.24 suggests some interaction between the unpaired electrons on the uranium atoms in 5T-1 corresponding to half-bond components. In the next $\mathrm{Cp}_{2} \mathrm{U}_{2}(\mathrm{CO})_{5}$ structure 5S-2 the combination of a singlet spin state and a formal $\mathrm{U}-\mathrm{U}$ single bond implies the +5 uranium oxidation state with greater reduction of the bridging $\eta^{2}-\mu-\mathrm{CO}$ groups to avoid unpaired electrons. 
The next $\mathrm{Cp}_{2} \mathrm{U}_{2}(\mathrm{CO})_{5}$ structure 5S-3, lying $9.9 \mathrm{kcal} / \mathrm{mol}$ in energy above 5T-1, has only three bridging $\eta^{2}-\mu$-CO groups (Figure 5 and Table 4). In addition, a terminal $\mathrm{CO}$ group is bonded to each uranium atom. The $\mathrm{U}=\mathrm{U}$ distance of $3.289 \AA$ in $5 \mathrm{~S}-3$, corresponding to a WBI of 1.84, suggests that all four electrons in two U(IV) atoms in 5S-3 are fully paired to form a $\mathrm{U}=\mathrm{U}$ double bond consistent with the singlet spin state.

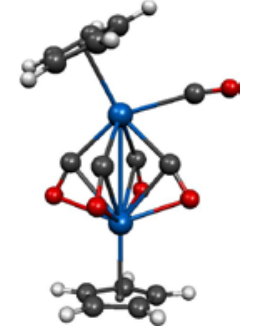

$5 \mathrm{~T}-1$

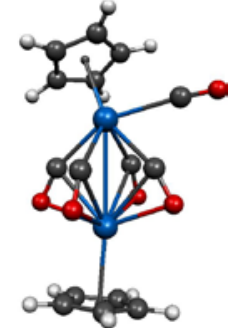

5S-2

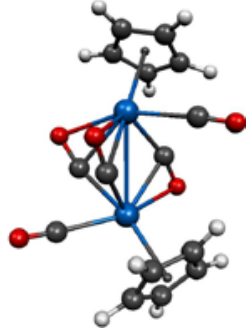

$5 S-3$

\section{$0.0 \mathrm{kcal} / \mathrm{mol} \quad 7.4 \mathrm{kcal} / \mathrm{mol} \quad 9.9 \mathrm{kcal} / \mathrm{mol}$}

Figure 5. The three lowest energy $\mathrm{Cp}_{2} \mathrm{U}_{2}(\mathrm{CO})_{5}$ structures.

Table 4. The three $\mathrm{Cp}_{2} \mathrm{U}_{2}(\mathrm{CO})_{5}$ structures up to $11 \mathrm{kcal} / \mathrm{mol}$ in energy.

\begin{tabular}{cccccccc}
\hline Structure & $\begin{array}{c}\Delta \mathrm{E} \\
(\mathrm{kcal} / \mathrm{mol})\end{array}$ & $\begin{array}{c}\mathrm{U}-\mathrm{U} \\
\text { distance }(\AA)\end{array}$ & $\begin{array}{c}\text { Wiberg bond } \\
\text { index (WBI) }\end{array}$ & $\begin{array}{c}\text { Mayer bond } \\
\text { order (MBO) }\end{array}$ & $\begin{array}{c}\text { U-U bond } \\
\text { order }\end{array}$ & $\begin{array}{c}\text { Mulliken } \\
\text { spin density }\end{array}$ & $\begin{array}{c}\text { Cp-U-U-Cp } \\
\text { Dihedral, }^{\circ}\end{array}$ \\
\hline $\mathbf{5 T - 1}$ & 0.0 & 3.433 & 1.24 & 1.77 & $2 / 2$ & $0.58 / 1.57$ & 175.6 \\
$\mathbf{5 S - 2}$ & 7.4 & 3.373 & 1.02 & 1.19 & 1 & - & 96.6 \\
$\mathbf{5 S - 3}$ & 9.9 & 3.289 & 1.84 & 1.20 & 2 & - & 109.7 \\
\hline
\end{tabular}

${ }^{a}$ The spin density of the uranium atom directly bonded to the most carbon atoms is listed first.

\subsection{Carbonyl Vibrational Frequencies of the $\mathrm{Cp}_{2} \mathrm{U}_{2}(\mathrm{CO})_{n}(n=2,3,4,5)$ Structures}

The infrared $v(\mathrm{CO})$ frequencies of the $\mathrm{Cp}_{2} \mathrm{U}_{2}(\mathrm{CO})_{n}(n=2,3,4,5)$ structures were examined for comparison with the previously studied ${ }^{21} \mathrm{Cp}_{2} \mathrm{Th}_{2}(\mathrm{CO})_{n}$ derivatives (Table 5). Most significantly, the $v(\mathrm{CO})$ frequencies of the ubiquitous bridging $\eta^{2}-\mu-\mathrm{CO}$ groups in the $\mathrm{Cp}_{2} \mathrm{U}_{2}(\mathrm{CO})_{n}$ structures are much lower than those of either terminal or bridging $\mathrm{CO}$ groups in d-block transition metal complexes. However, they increase somewhat going from the dicarbonyls $\mathrm{Cp}_{2} \mathrm{U}_{2}(\mathrm{CO})_{2}$ to the tricarbonyls and tetracarbonyls $\mathrm{Cp}_{2} \mathrm{U}_{2}(\mathrm{CO})_{n}(n=$ 3 , 4). Thus in the dicarbonyls $\mathrm{Cp}_{2} \mathrm{U}_{2}(\mathrm{CO})_{2}$ the $v(\mathrm{CO})$ frequencies for the $\eta^{2}-\mu$-CO groups range from 1314 to $1386 \mathrm{~cm}^{-1}$, those in the tricarbonyls $\mathrm{Cp}_{2} \mathrm{U}_{2}(\mathrm{CO})_{3}$ range from 1496 to $1660 \mathrm{~cm}^{-1}$, and those in the tetracarbonyls $\mathrm{Cp}_{2} \mathrm{U}_{2}(\mathrm{CO})_{4}$ range from 1380 to $1560 \mathrm{~cm}^{-1}$. The $v(\mathrm{CO})$ frequencies of the terminal $\mathrm{CO}$ groups in the $\mathrm{Cp}_{2} \mathrm{U}_{2}(\mathrm{CO})_{n}$ structures range 
from 1900 to $1962 \mathrm{~cm}^{-1}$, which are similar to the terminal $v(\mathrm{CO})$ frequencies in d-block transition metal carbonyl derivatives.

Table 5. Harmonic $v(\mathrm{CO})$ vibrational frequencies (in $\mathrm{cm}^{-1}$ ) and infrared intensities (in parentheses, in $\mathrm{km} / \mathrm{mol}$ ) for the $\mathrm{Cp}_{2} \mathrm{U}_{2}(\mathrm{CO})_{n}$ derivatives and some analogous $\mathrm{Cp}_{2} \mathrm{Th}_{2}(\mathrm{CO})_{n}$ derivatives.

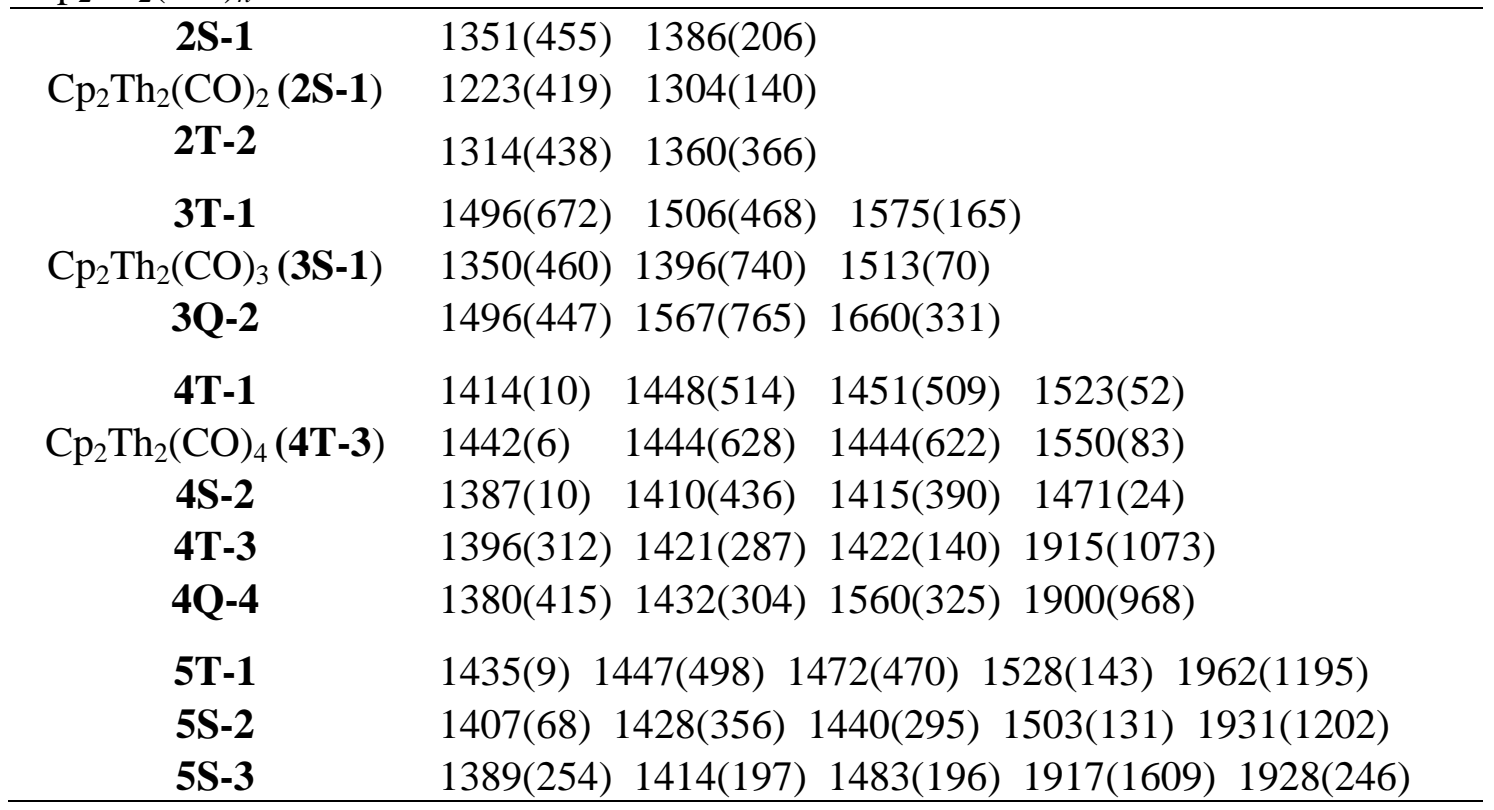

The previously predicted $v(\mathrm{CO})$ frequencies of $\mathrm{Cp}_{2} \mathrm{Th}_{2}(\mathrm{CO})_{n}(n=2,3,4)$ were compared with those of $\mathrm{Cp}_{2} \mathrm{U}_{2}(\mathrm{CO})_{n}$ structures having similar arrangements of $\eta^{2}-\mu-\mathrm{CO}$ groups. In this connection the four $v(\mathrm{CO})$ frequencies and their relative intensities of the triplet $\mathrm{Cp}_{2} \mathrm{U}_{2}\left(\eta^{2}-\mu-\mathrm{CO}\right)_{4}$ structure $\mathbf{4 T - 1}$ are remarkably similar to those previously found for the triplet $\mathrm{Cp}_{2} \mathrm{Th}_{2}\left(\eta^{2}-\mu-\mathrm{CO}\right)_{4}$ structure (4T-3 in reference 21) likewise having four separate bridging $\eta^{2}-\mu-\mathrm{CO}$ groups.

\section{Summary}

All or almost all of the CO groups in the low-energy $\mathrm{Cp}_{2} \mathrm{U}_{2}(\mathrm{CO})_{n}(n=2,3,4)$ structures are bridging $\eta^{2}-\mu-\mathrm{CO}$ groups. No examples of coupling of $\mathrm{CO}$ groups to form $\mathrm{C}_{2} \mathrm{O}_{2}$ ligands are found in any of these structures in contrast to the previously studied ${ }^{21}$ $\mathrm{Cp}_{2} \mathrm{Th}_{2}(\mathrm{CO})_{4}$ system where $\mathrm{CO}$ coupling to form $\mathrm{C}_{2} \mathrm{O}_{2}$ ligands is observed. This can be related to the accessibility of oxidation states greater than +4 for uranium in contrast to thorium. Thus $\mathrm{CpU}$ units can provide enough electrons to reduce at least two $\mathrm{CO}$ groups per uranium atom fully to $\mathrm{CO}^{2-}$ dianions. The ability of organouranium compounds to reductively couple $\mathrm{CO}$ units to $\mathrm{C}_{n} \mathrm{O}_{n}{ }^{2-}$ units therefore requires additional anionic 
hydrocarbon ligands to limit the number of uranium electrons available for donation to CO. This is exemplified by the use of substituted $\mathrm{CpU}\left(\mathrm{C}_{8} \mathrm{H}_{8}\right)$ systems rather than simple $\mathrm{CpU}$ or $\mathrm{C}_{8} \mathrm{H}_{8} \mathrm{U}$ systems for reductive coupling of $\mathrm{CO}$ groups in the experimental work of Cloke and co-workers. ${ }^{13,14,15}$

The low-energy $\mathrm{Cp}_{2} \mathrm{U}_{2}(\mathrm{CO})_{n}(n=2,3,4)$ structures retain uranium valence electrons even after partial donation of uranium electrons to reduce $\mathrm{Cp}$ to $\mathrm{Cp}^{-}$and $\mathrm{CO}$ to $\mathrm{CO}^{2-}$. This leads to a rich and complicated variety of U-U bonding modes and spin states from singlet to quintet in the lowest energy structures. Of particular interest is a variety of formal uranium-uranium multiple bonds containing multiple single-electron half-bond components. Such $\mathrm{Cp}_{2} \mathrm{U}_{2}(\mathrm{CO})_{n}$ derivatives are molecular species containing uraniumuranium multiple bonds having some of the features of the formal quintuple bond of diuranium, $\mathrm{U}_{2}$, in which a typical $\sigma+2 \pi$ triple bond similar to the $\mathrm{C} \equiv \mathrm{C}$ triple bond of acetylene is supplemented by no less than four separate one-electron half-bonds.

Acknowledgment. Funding from the Romanian Ministry of Education and Research (Grant PN-II-ID-PCE-2012-4-0488), and the U. S. National Science Foundation (Grant CHE-1057466) is gratefully acknowledged. Additional computational resources were provided by the high-performance computational facility MADECIP, POSCCE, COD SMIS 48801/1862 co-financed by the European Regional Development Fund of the European Union.

Supporting Information. Table S1: Initial $\mathrm{Cp}_{2} \mathrm{U}_{2}(\mathrm{CO})_{n}$ structures; Table S2A: Distance table for the lowest-lying $\mathrm{Cp}_{2} \mathrm{U}_{2}(\mathrm{CO})_{2}$ structures; Table S2B: Energy rank for all of the $\mathrm{Cp}_{2} \mathrm{U}_{2}(\mathrm{CO})_{2}$ structures; Table S3A: Distance table for the lowest-lying $\mathrm{Cp}_{2} \mathrm{U}_{2}(\mathrm{CO})_{3}$ structures; Table S3B: Energy rank for all of the $\mathrm{Cp}_{2} \mathrm{U}_{2}(\mathrm{CO})_{3}$ structures; Table S4A: Distance table for the lowest-lying $\mathrm{Cp}_{2} \mathrm{U}_{2}(\mathrm{CO})_{4}$ structures; Table S4B: Energy rank for all of the $\mathrm{Cp}_{2} \mathrm{U}_{2}(\mathrm{CO})_{4}$ structures; Table S5A: Distance table for the lowest-lying $\mathrm{Cp}_{2} \mathrm{U}_{2}(\mathrm{CO})_{5}$ structures; Table S5B: Energy rank for all of the $\mathrm{Cp}_{2} \mathrm{U}_{2}(\mathrm{CO})_{5}$ structures; Table S6: Frontier molecular orbitals of the lowest energy $\mathrm{Cp}_{2} \mathrm{U}_{2}(\mathrm{CO})_{2}$ structures. Table S7: Frontier molecular orbitals of the lowest energy $\mathrm{Cp}_{2} \mathrm{U}_{2}(\mathrm{CO})_{3}$ structures. Table S8: Frontier molecular orbitals of the lowest energy $\mathrm{Cp}_{2} \mathrm{U}_{2}(\mathrm{CO})_{4}$ structures. Table S9: Frontier molecular orbitals of the lowest energy $\mathrm{Cp}_{2} \mathrm{U}_{2}(\mathrm{CO})_{5}$ structures. Complete Gaussian09 reference (reference 36); Separate concatenated xyz file containing all of the optimized $\mathrm{Cp}_{2} \mathrm{U}_{2}(\mathrm{CO})_{n}$ structures. 


\section{Literature References}

(1) F. Calderazzo, in Encyclopedia of Inorganic Chemistry, $2^{\text {nd }}$ Edition, ed. King, R. B., Wiley, Chichester, (2005), pp. 764-781.

(2) C. Elschenbroich, Organometallics, Wiley-VCH, Weinheim, (2006): Chapter 14.4.

(3) R. K. Szilagyi, G. Frenking, Organometallics 16 (1997) 4807.

(4) A. Diefenbach, F. M. Bickelhaupt, G. Frenking, J. Am. Chem. Soc. 122 (2000) 6449.

(5) J. G. Brennan, R. A. Andersen, J. L. Robbins, J. Am. Chem. Soc. 108 (1986) 335.

(6) J. Parry, E. Carmona, S. Coles, M. Hursthouse, J. Am. Chem. Soc. 117 (1995) 2649.

(7) M. del Mar Conejo, J. S. Parry, E. Carmona, M. Schultz, J. G. Brennann, S. M. Beshouri, R. A. Andersen, R. D. Rogers, S. Coles, M. Hursthouse, Chem. Eur. J. 5 (1999) 3000.

(8) W. J. Evans, S. A. Kozimovr, G. W. Nyce, J. W. Ziller, J. Am. Chem. Soc. 125 (2003) 13831.

(9) M. Zhou, L. Andrews, J. Li, B. E. Bursten, J. Am. Chem. Soc. 121 (1999) 12188.

(10) J. Li, B. E. Bursten, M. Zhou, L. Andrews, Inorg. Chem. 40 (2001) 5448.

(11) L. Andrews, B. Liang, J. Li, B. E. Bursten, J. Am. Chem. Soc. 125 (2003) 3126.

(12) N. Tsoureas, O. T. Summerscales, F. G. N. Cloke, S. M. Roe, Organometallics 32 (2013) 1353.

(13) A. S. Frey, F. G. N. Cloke, P. B. Hitchcock, I. J. Day, J. C. Green, G. Aitken, J. Am. Chem. Soc. 130 (2008) 13681.

(14) O. T. Summerscales, F. G. N. Cloke, P. B. Hitchcock, J. C. Green, N. Hazari, Science 311 (2006) 829.

(15) O. T. Summerscales, F. G. N. Cloke, P. B. Hitchcock J. C., Green, N. Hazari, J. Am. Chem. Soc. 128 (2006) 9602.

(16) P. L. Arnold, Z. R. Turner, R. M. Bellabarba, R. P. Tooze, Chem. Sci. 2 (2011) 77.

(17) D. McKay, A. S. P. Frey, J. C. Green, F. G. N. Cloke, L. Maron, Chem. Comm. 48 (2012) 4118.

(18) L. Gagliardi, B. O. Roos, Nature 433 (2005) 848.

(19) B. O. Roos, P.-A. Malmqvist,; L. Gagliardi, J. Am. Chem. Soc. 128 (2006) 17000.

(20) C.-Z. Wang, J. K. Gibson, J.-H .Lan, Q.-Y Wu,. Y.-L. Zhao, J. Li, Z.-F. Chai, W.Q. Shi, Dalton Trans. 44 (2015) 17045. 
(21) H. Li, H. Feng, W. Sun, R. B. King, H. F. Schaefer, Inorg. Chem. 52 (2013) 6893.

(22) H. Li, H. Feng, W. Sun, Q. Fan, , R. B. King, H. F Schaefer,. New J. Chem. 38 (2014) 6031.

(23) A. F. Hepp, J. P. Blaha, C. Lewis, M. S. Wrighton, Organometallics 3 (1984) 174.

(24) J. V. Caspar, T. J. Meyer, J. Am. Chem. Soc. 102 (1980) 7794.

(25) R. H. Hooker, K. A. Mahmoud, A. J. Rest, Chem. Commun. (1983) 1022.

(26) A. D. Becke, Phys. Rev. A 38 (1988) 3098.

(27) J. P. Perdew, Phys. Rev. B 33 (1986) 8822.

(28) A. Schaefer, H. Horn, R. Ahlrichs, J. Chem. Phys. 97 (1992) 2571.

(29) A. Schaefer, C. Huber, R. Ahlrichs, J. Chem. Phys. 100 (1994) 5829.

(30) X. Cao, M. Dolg, H. Stoll, J. Chem. Phys. 118 (2003) 487.

(31) X. Cao, M. Dolg, J. Molec. Struct. (Theochem) 673 (2004) 203.

(32) M. Dolg, H. Stoll, H. Preuss, J. Chem. Phys. 100 (1994) 7535.

(33) C. van Wuellen, J. Chem. Phys. 109 (1998) 392.

(34) D. A. Pantazis, F. Neese, J. Chem. Theory Comput. 7 (2011) 677.

(35) F. Neese "The ORCA program system"; Wiley interdisciplinary Reviews Computational Molecular Science 2 (2012) 73-78.

(36) Gaussian 09 (Revision E.01), Gaussian, Inc., Wallingford, CT, (2009). The complete reference is given in the Supporting Information

(37) F. Weinhold, C. R. Landis, Valency and Bonding: A Natural Bond Order DonorAcceptor Perspective, Cambridge University Press, Cambridge, England, U. K., (2005) pp. 32-36.

(38) I. Mayer, J. Comput. Chem., 28 (2007) 204.

(39) H. Y. Wang, Y. Xie, R. B. King, H. F. Schaefer, J. Am. Chem. Soc. 128 (2006) 11376. 


\section{Graphical Abstract}

Metal-metal Multiple Bonds The low-energy $\mathrm{Cp}_{2} \mathrm{U}_{2}(\mathrm{CO})_{n}(n=2,3,4)$ with "Half-Bond" Components structures have entirely or almost entirely in Paramagnetic Organo- bridging $\eta^{2}-\mu-\mathrm{CO}$ groups and do not metallics of $\mathbf{f}$-Block Metals: exhibit $\mathrm{CO}$ coupling. Spin states from Cyclopentadienyluranium Carbonyls as Molecular Relatives of Diuranium

Ciprian Coşar, Amr A. A. Attia, Alexandru Lupan,* and R. Bruce King* singlet to quintet are observed as well as a variety of U-U bonding modes including formal multiple bonds containing oneelectron half-bonds in paramagnetic structures.

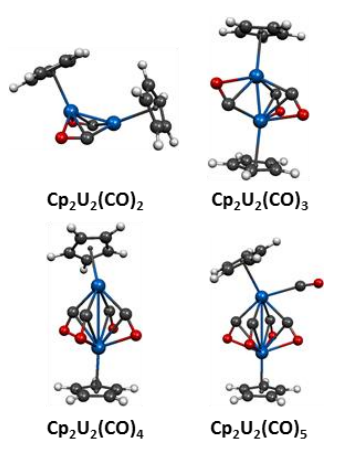

